\title{
Neuroophthalmological outcomes associated with use of the Pipeline Embolization Device: analysis of the PUFS trial results
}

\author{
Daniel H. Sahlein, MD, ${ }^{1,2}$ Mohammad Fouladvand, MD, ${ }^{1,3}$ Tibor Becske, MD, ${ }^{1,2}$ Isil Saatci, MD, ${ }^{4}$ \\ Cameron G. McDougall, MD, ${ }^{5}$ István Szikora, MD, PhD, ${ }^{6}$ Giuseppe Lanzino, MD, ${ }^{7}$ \\ Christopher J. Moran, MD, ${ }^{8}$ Henry H. Woo, MD, ${ }^{9}$ Demetrius K. Lopes, MD, ${ }^{10}$ Aaron L. Berez, MD, ${ }^{12}$ \\ Daniel J. Cher, MD, ${ }^{11}$ Adnan H. Siddiqui, MD, PhD, ${ }^{13}$ Elad I. Levy, MD, ${ }^{13}$ Felipe C. Albuquerque, MD, ${ }^{5}$ \\ David J. Fiorella, MD, PhD, ${ }^{9}$ Zsolt Berentei, MD, ${ }^{6}$ Miklos Marosfoi, MD, ${ }^{6}$ Saruhan H. Cekirge, MD, ${ }^{14}$ \\ David F. Kallmes, MD, ${ }^{7}$ and Peter K. Nelson, MD²,15
}

Departments of ${ }^{1}$ Neurology, ${ }^{2}$ Radiology, ${ }^{3}$ Ophthalmology, and ${ }^{15}$ Neurosurgery, New York University Langone Medical Center, New York; ${ }^{9}$ Department of Neurological Surgery, Stony Brook University, Stony Brook; ${ }^{3}$ Department of Neurosurgery, University at Buffalo, Buffalo, New York; ${ }^{4}$ Department of Interventional Neuroradiology, Koru Hospitals, Ankara; ${ }^{14}$ Department of Interventional Neuroradiology, Bayindir Hospitals, Ankara/Istanbul, Turkey; ${ }^{5}$ Division of Neurological Surgery, Barrow Neurological Institute, Phoenix, Arizona; ${ }^{6}$ National Institute of Neurosciences, Budapest, Hungary; ${ }^{7}$ Department of Neurosurgery, Mayo Clinic, Rochester, Minnesota; ${ }^{2}$ Division of Interventional Neuroradiology, Mallinckrodt Institute of Radiology, Washington University School of Medicine, St. Louis, Missouri; ${ }^{10}$ Department of Neurological Surgery, Rush University, Chicago, Illinois; ${ }^{11}$ Wild Iris Consulting LLC, Palo Alto; and ${ }^{12}$ Alembic LLC, Mountain View, California

ABBREVIATIONS APD = afferent pupillary defect; $C N=$ cranial nerve; ICA = internal carotid artery; PED = Pipeline Embolization Device; PUFS = Pipeline for Uncoilable or Failed Aneurysms; $V A=$ visual acuity; $V F=$ visual field.

SUBMITTED August 1, 2014. ACCEPTED December 18, 2014.

INCLUDE WHEN CITING Published online July 10, 2015; DOI: 10.3171/2014.12.JNS141777.

DISCLOSURE Dr. Becske is a consultant/proctor in the use of the Pipeline Embolization Device for Covidien. Dr. Saatci's institution received fees for participation in review activities from Chestnut Medical, and she received consultancy fees from ev3/Covidien. Dr. McDougall received consultancy fees from the Covidien Medical Advisory Board. Dr. Szikora and his institution received consulting fees or honoraria from Chestnut Medical, and he received consultancy fees from Stryker Neurovascular and ev3/ Covidien and speaker's and service fees for being on speakers' bureaus of Stryker Neurovascular and ev3/Covidien. Dr. Lanzino's institution received consulting fees or honoraria from ev3/Covidien and support for travel to meetings for the study or other purposes from ev3/Covidien for presentation to a FDA panel; his institution received an unrestricted educational grant from ev3/Covidien. Dr. Moran is a chief medical officer for Covidien, and he received fees from ev3/Covidien for lectures and for development of educational presentations. Dr. Woo's institution received funds for grants or for pending grants from Siemens and from MicroVention; he received royalties paid by Codman and Shurtleff for an acute stroke device after acquisition of Revasc and travel/accommodations/meeting expenses unrelated to this study from Siemens; and he is the President/CFO of Vascular Simulations. Dr. Berez was an employee of Chestnut Medical and ev3/Covidien and received patent royalties from Covidien; he has stock/stock options in Chestnut Medical and Covidien, and is a founder and employee of Chestnut; he received travel/accommodations/meeting expenses unrelated to this study from Chestnut Medical and ev3/Covidien; and he is the founder and CEO of Chestnut Medical, the company that developed the PED, and is the inventor named on the relevant patents. Dr. Cher was an employee of Chestnut Medical and ev3/Covidien during the data collection phase of this study, is currently a consultant for Covidien/ Medtronic, and he had stock/stock options in Chestnut Medical and Covidien. Dr. Siddiqui received financial compensation from Codman \& Shurtleff for serving on its advisory board and from Codman \& Shurtleff, Concentric Medical, ev3/Covidien, Guide Point Global Consulting, and Penumbra for consultancy; he has grants or grants pending from the National Institutes of Health and the University at Buffalo (SUNY); he received fees for lectures and for serving on speakers bureaus from Codman \& Shurtleff and Genetech; he received funds for stock/stock options from Hotspur, Intratech Medical, Stim-Sox, and Valor Medical; his institution received funds for travel/accommodations/ meeting expenses unrelated to this study from the 44th Neuroendovascular Complication Meeting and Asia Pacific Stroke Conference; he received honoraria from Abbott Vascular, American Association of Neurological Surgeons' courses, and Genetech; and he has a nonfinancial relationship with Penumbra and serves on the National Steering Committee for 3D Separator Trial. Dr. Levy is a board member of Codman \& Shurtleff; received consultancy fees from Codman \& Shurtleff, ev3/Covidien, and TheraSyn Sensors; provided expert testimony for Medical Legal Review; has grants or grants pending from SARIS, Codman \& Shurtleff, ev3/Covidien, and Boston Scientific; received honoraria and lecture fees from Boston Scientific; received funds from stocks or stock options from Intratech Medical, Mynx; and received fees for carotid stent training from Abbott Vascular. Dr. Fiorella received grant support from SAMMPRIS-NIH and consultancy fees from Codman \& Shurtleff, ev3/Covidien, NFocus, and Cordis; has grants or grants pending from Siemens, MicroVention; and holds stocks or stock options from Vascular Simulators. Dr. Cekirge's institution received financial compensation for review activities from Chestnut Medical, and he received consultancy fees from ev3/Covidien and MicroVention. Dr. Kallmes's institution received a grant from Chestnut Medical and ev3/Covidien for funding of a clinical trial; support for travel to meetings for the study or other purposes from MictroVention; consultancy fees not related to this study from Medtronic and ev3/ Covidien; financial support for grants or pending grants from ev3/Covidien, MicroVention, Sequent, Micrus, and Benvenue Medical for preclinical studies and clinical trials; development funds for educational presentations from ev3/Covidien and CareFusion; and travel/accommodations/meeting expenses unrelated to this study from MicroVention and ev3/Covidien; and he received royalties from the UVA Patent Foundation. Dr. Nelson is a consultant/proctor in the use of the Pipeline Embolization Device for Covidien. The PUFS trial was supported by Chestnut Medical and ev3 (Covidien). 
OBJECT Neuroophthalmological morbidity is commonly associated with large and giant cavernous and supraclinoid internal carotid artery (ICA) aneurysms. The authors sought to evaluate the neuroophthalmological outcomes after treatment of these aneurysms with the Pipeline Embolization Device (PED).

METHODS The Pipeline for Uncoilable or Failed Aneurysms (PUFS) trial was an international, multicenter prospective trial evaluating the safety and efficacy of the PED. All patients underwent complete neuroophthalmological examinations both before the PED procedure and at a 6-month follow-up. All examinations were performed for the purpose of this study and according to study criteria.

RESULTS In total, 108 patients were treated in the PUFS trial, 98 of whom had complete neuroophthalmological follow-up. Of the patients with complete follow-up, 39 (40\%) presented with a neuroophthalmological baseline deficit that was presumed to be attributable to the aneurysm, and patients with these baseline deficits had significantly larger aneurysms. In 25 of these patients (64\%), the baseline deficit showed at least some improvement 6 months after PED treatment, whereas in 1 patient (2.6\%), the deficits only worsened. In 5 patients (5\%), new deficits had developed at the 6 -month follow-up, while in another 6 patients $(6 \%)$, deficits that were not originally assumed to be related to the aneurysm had improved by that time. A history of diabetes was associated with failure of the baseline deficits to improve after the treatment. The aneurysm maximum diameter was significantly larger in patients with a new deficit or a worse baseline deficit at 6 months postprocedure.

CONCLUSIONS Patients treated with the PED for large and giant ICA aneurysms had excellent neuroophthalmological outcomes 6 months after the procedure, with deficits improving in most of the patients, very few deficits worsening, and few new deficits developing.

Clinical trial registration no.: NCT00777088 (clinicaltrials.gov)

http://thejns.org/doi/abs/10.3171/2014.12.JNS141777

KEY WORDS neuroophthalmology; aneurysm; flow diversion; Pipeline Embolization Device; aneurysm embolization; vascular disorders

A LTHOUGH the risks of mortality or severe neurological morbidity from large and giant cavernous and supraclinoid internal carotid artery (ICA) aneurysms are low, $, 7,13$ they often are associated with substantial neuroophthalmological disorders and facial pain., ${ }^{4,8,13}$ Mass effects from large and giant aneurysms of the ICA involving the petrous through supraclinoid segments may cause cranial neuropathies that affect cranial nerves $(\mathrm{CNs})$ III, IV, V, and VI. In addition, optic neuropathy may develop from direct compression of the optic nerve, resulting in visual field (VF) deficits, visual acuity (VA) problems, and/or afferent pupillary defects (APDs). Although the effects of both endovascular and surgical aneurysm treatments on neuroophthalmological morbidity rates have been studied, , 1,3-5,8,9,11,13,15,16 the literature on this matter as a whole is diminished by the lack of prospective studies, the variable length of reported follow-up, and the lack of consensus on fundamental neuroophthalmological endpoints; for example, there is a lack of agreement whether objective findings such as "ophthalmoparesis" should be grouped with subjective findings such as "diplopia."

In April 2011, the Pipeline Embolization Device (PED, Covidien) received FDA clearance for the endovascular reconstruction of large and giant wide-necked aneurysms of the ICA. The safety and efficacy of the PED has been unequivocally demonstrated for these aneurysms of the cavernous and supraclinoid segments of the ICA.,10 Although the treatment of large and giant ICA aneurysms with mass-occupying coils is very frequently associated with negative neuroophthalmological outcomes ${ }^{17}-\mathrm{ob}-$ served with both hydrogel-coated coils $\mathrm{s}^{12,14}$ and platinum coils ${ }^{5}$ - the absence of an intrasaccular element in PEDbased treatment theoretically permits a reduction in mass effect accompanying aneurysmal involution with the potential to facilitate resolution of compression-related $\mathrm{CN}$ deficits and optic neuropathy. The Pipeline for Uncoilable or Failed Aneurysms (PUFS) is a prospective, multicenter, and single-arm clinical trial of the PED for the treatment of unruptured large and giant aneurysms of the ICA. Herein, we present an analysis of the baseline and 6-month neuroophthalmological findings from the trial to determine whether PED treatment improves neuroophthalmological symptoms associated with the target aneurysm.

\section{Methods \\ Design}

The details of the PUFS trial, which was approved by the internal review boards of all institutions involved, have been published previously. ${ }^{2}$ Briefly, PUFS is an international, multicenter clinical trial conducted at 10 centers: 8 in the United States, 1 in Hungary, and 1 in Turkey.

\section{Patients}

Patients were included in this study if they had an aneurysm arising from the ICA (petrous through the superior hypophysial segments and proximal to the posterior communicating segment) that measured at least $10 \mathrm{~mm}$ in maximum diameter and also had an aneurysm neck of at least $4 \mathrm{~mm}$ in one dimension. Patients were excluded if they had had a subarachnoid hemorrhage in the previous 60 days, any intracranial hemorrhage, or a major operation within the last 42 days; a history of bleeding disorders or low platelet count; undergone placement of an indwelling stent at the target aneurysm site; a contraindication to CT 
and MRI; an allergy to platinum or cobalt/chromium alloys; evidence of an active infection; or major stenosis of the ipsilateral carotid artery. Patients with recurrent intracranial aneurysms after surgical or endovascular therapy were included, except if an indwelling stent was present in the parent artery. All study participants provided written informed consent before study participation.

\section{Assessments}

Before a PED placement, all patients underwent a baseline neurological examination, which included a detailed neuroophthalmological assessment to identify any oculomotor, or VA, and/or VF deficits. The neuroophthalmological examination was performed by neuroophthalmologists at each study site and included a fundus photograph, VA examination by Snellen with correction, VF examination by static perimetry, and a detailed $\mathrm{CN}$ examination with a prism, if required. Patients underwent a repeat examination at 180 days after PED placement. All neuroophthalmological data were independently reanalyzed by a single neuroophthalmologist (M.F.) to ensure that baseline and follow-up examinations adhered to the study protocol. The baseline findings of the neuroophthalmological examination were recorded as normal, abnormal and probably related to the aneurysm, abnormal and probably unrelated to the aneurysm, or abnormal with unknown relationship to the aneurysm. Only those neuroophthalmological findings that were presumed to be related to the aneurysm were included in the analysis as aneurysm related. At the followup, elements of the neuroophthalmological examination were graded as completely resolved (100\% improvement), highly improved ( $\geq 50 \%$ improvement), moderately improved (20\%-50\% improvement), stable ( $<20 \%$ improvement), moderately worse (20\%-50\% worsened), markedly worse ( $\geq 50 \%$ worsened), or cannot tell because of equivocal or otherwise unclear examination findings.

The procedural efficacy (degree of occlusion) for all aneurysms was assessed at 6 months postprocedure by a core laboratory using a previously published scale (complete occlusion, residual neck, or residual aneurysm). ${ }^{2,13}$ Neuroophthalmological outcome was analyzed as a function of procedural efficacy.

\section{Statistical Analysis}

Categorical variables were analyzed with chi-square or Fisher's exact tests as appropriate. Continuous variables were analyzed with Student's t-test for 2-group comparisons, and 1-way ANOVA with a post hoc Tukey's test was used for 3 or more group comparisons.

\section{Results}

In total, 108 patients were treated in the PUFS trial. For several reasons, 10 of these patients were excluded from the 180-day neuroophthalmological follow-up (Table 1). Therefore, the analysis included 98 patients (91\%) for whom complete follow-up data were available. The demographics and baseline aneurysm characteristics of the included patients are shown in Table 2. The average age of the patients was $56.4 \pm 11.6$ years, and 88 of the patients (90\%) were female.
TABLE 1. Reasons for exclusion of patients from this study

\begin{tabular}{cc}
\hline Reason for Elimination From Analysis & No. of Patients (\%) \\
\hline Death & $3(3)$ \\
\hline Declined 180-day exam & $2(2)$ \\
\hline No 180-day exam & $1(1)$ \\
\hline Nonparticipatory & $1(1)$ \\
\hline Not treated w/ PED & $1(1)$ \\
\hline Withdrawal from study & $1(1)$ \\
\hline Loss to follow-up & $1(1)$ \\
\hline
\end{tabular}

Thirty-nine patients (40\%) had baseline neuroophthalmological deficits at the time of the PED treatment, and several of these patients had multiple deficits. Also included in Table 2 are the results of a univariate analysis of baseline clinical and aneurysm characteristics that were associated with a presentation of a baseline deficit. Those with a deficit tended to be older (age $58.0 \pm 10.8$ years) than those with no baseline deficits $(55.3 \pm 12.0$ years), but this age difference did not reach statistical significance $(p$ $=0.26$ ). We also noted a trend toward statistical significance of the association between aneurysm location and presentation of symptoms $(\mathrm{p}=0.058)$, with a higher proportion of patients with cavernous segment aneurysms exhibiting neuroophthalmological deficits (57\%) than those with aneurysms of the petrous (0\%), superior hypophysial (22\%), paraophthalmic (27\%), or supraclinoid $(25 \%)$ segments. The size of the aneurysm (its maximum dimension) was most statistically significantly associated with a baseline deficit $(22.0 \pm 5.9 \mathrm{~mm}$ for patients with deficits vs $15.7 \pm 5.9 \mathrm{~mm}$ for those with no deficits, $\mathrm{p}<0.001)$. Dome size $(16.8 \pm 5.2 \mathrm{~mm}$ for patients with deficits vs $13.3 \pm 5.5$ $\mathrm{mm}$ for those with no deficits, $\mathrm{p}=0.003$ ) and, to a lesser extent, neck size $(10.0 \pm 4.6 \mathrm{~mm}$ for those with deficits vs $8.1 \pm 4.3 \mathrm{~mm}$ for those with no deficit, $\mathrm{p}=0.032$ ) were also significantly associated with baseline deficits.

Figure 1 shows the results of PED treatment of a giant, wide-neck paraophthalmic segment aneurysm of the left ICA, with both angiographically defined vascular exclusion of the aneurysm 6 months after treatment and involution of the excluded aneurysm sack. Three sequential transaxial CT images immediately after PED placement (Fig. 1, panels D-F) show contrast layering within the giant aneurysm and mass effect on the left optic nerve and inferomedial frontal lobe. Six months after treatment (panels G-I), the aneurysm sac had completely resolved (disappeared on CT). Three frontal oblique angiographic images show the aneurysm (panel A), the stent construct (immediately after placement in the left ICA) (panel B), and complete angiographically defined occlusion of the aneurysm at the 6-month follow-up (panel C).

The relationship between individual baseline deficits and aneurysm location is shown in Table 3. A statistically significant predominance of cavernous segment aneurysms was detected in patients with symptoms of CN III or CN VI palsies.

The 6-month outcomes for all patients with neuroophthalmological findings during the course of this study are pictorially summarized in Fig. 2. One patient with a central 
TABLE 2. Patient demographics and aneurysm characteristics ordered by baseline neuroophthalmological findings

\begin{tabular}{|c|c|c|c|c|}
\hline \multirow[b]{2}{*}{ Variable } & \multicolumn{3}{|c|}{ Patients } & \multirow[b]{2}{*}{$\mathrm{p}$ Value } \\
\hline & All & w/ Baseline Deficit§ & w/o Baseline Deficit§ & \\
\hline No. of patients in group (\%) & $98(100.0)$ & $39(39.8)$ & $59(60.2)$ & NA \\
\hline Female sex $(\%)$ & $88(89.8)$ & $35(89.7)$ & $53(89.8)$ & $1.0^{*}$ \\
\hline Mean age in yrs (SD) & $56.4(11.6)$ & $58.0(10.8)$ & $55.3(12.0)$ & $0.26 \dagger$ \\
\hline Mean BMI (SD) & $27.1(5.3)$ & $27.0(5.3)$ & $27.1(5.3)$ & $0.94 \dagger$ \\
\hline \multicolumn{5}{|l|}{ Medical history, no. of pts (\%) } \\
\hline $\mathrm{SAH}$ & $6(6.1)$ & $4(10.3)$ & $2(3.4)$ & $0.21^{*}$ \\
\hline Hypertension & $52(53.1)$ & $24(61.5)$ & $28(47.5)$ & $0.31 \ddagger$ \\
\hline Cocaine use & $1(1.0)$ & $1(2.6)$ & $0(0.0)$ & $0.40^{*}$ \\
\hline Smoking & & & & $0.94 \ddagger$ \\
\hline Previous smoker & $27(27.6)$ & $10(25.6)$ & $17(28.8)$ & \\
\hline Current smoker & $29(29.6)$ & $12(30.8)$ & $17(28.8)$ & \\
\hline Coronary artery disease & $6(6.1)$ & $1(2.6)$ & $5(8.5)$ & $0.40^{*}$ \\
\hline Myocardial infarction & $3(3.1)$ & $0(0.0)$ & $3(5.1)$ & $0.43 \ddagger$ \\
\hline Diabetes mellitus & $7(7.1)$ & $4(10.3)$ & $3(5.1)$ & $0.46 \ddagger$ \\
\hline Aneurysm side (rt) & $49(50.0)$ & $17(43.6)$ & $32(54.2)$ & $0.41^{*}$ \\
\hline Aneurysm location, no. of pts (\%) & & & & $0.058 \ddagger$ \\
\hline Petrous & $4(4.1)$ & $0(0.0)$ & $4(6.8)$ & \\
\hline Cavernous & $42(42.9)$ & $24(61.5)$ & $18(30.5)$ & \\
\hline Carotid cave & $2(2.0)$ & $1(2.6)$ & $1(1.7)$ & \\
\hline Sup hypophysial & $9(9.2)$ & $2(5.1)$ & $7(11.9)$ & \\
\hline Lat clinoidal & $2(2.0)$ & $1(2.6)$ & $1(1.7)$ & \\
\hline Paraophthalmic & $30(30.6)$ & $8(20.5)$ & $22(37.3)$ & \\
\hline Supraclinoid & $8(8.2)$ & $2(5.1)$ & $6(10.2)$ & \\
\hline PCoA & $1(1.0)$ & $0(0.0)$ & $1(1.7)$ & \\
\hline \multicolumn{5}{|l|}{ Mean aneurysm size in mm (SD) } \\
\hline Neck & $8.8(4.5)$ & $10.0(4.6)$ & $8.1(4.3)$ & $0.032 \dagger$ \\
\hline Dome & $14.7(5.6)$ & $16.8(5.2)$ & $13.3(5.5)$ & $0.003 \dagger$ \\
\hline Max dimension & $18.2(6.6)$ & $22.0(5.9)$ & $15.7(5.9)$ & $<0.001 \dagger$ \\
\hline Neck-to-dome ratio & $1.8(0.7)$ & $1.80(0.56)$ & $1.77(0.72)$ & $0.79 \dagger$ \\
\hline $\begin{array}{l}\text { BMI }=\text { body mass index; } P C O A=\text { posterior } \\
\text { * The } p \text { value was determined with a } 2 \text {-sid } \\
\text { The } p \text { value was determined with an ind } \\
\text { The } p \text { value was determined with a chi-s } \\
\S \text { Presumed attributable to the target anel }\end{array}$ & $\begin{array}{l}\text { unicating arter } \\
\text { ner exact test. } \\
\text { ent samples t- } t \\
\text { test. }\end{array}$ & $=$ patients; $\mathrm{SAH}=$ suba & oid hemorrhage; Sup = & \\
\hline
\end{tabular}

retinal artery occlusion and resulting VF and VA deficits and an APD is not included on this chart because that outcome was adjudicated by an independent clinical events committee as being a thromboembolic event. Each row in Fig. 2 represents findings from an individual patient. Baseline deficits adjudicated as probably related to the aneurysm are shown in solid colors. Deficits that were not present at baseline but that appeared at 6 months postprocedure are indicated by colored rectangles with horizontal hatching. Also included (and depicted by colored rectangles with vertical hatching) are those baseline deficits that were initially presumed not to be likely related to the aneurysm but had improved at the 6-month follow-up, thereby suggesting that the original adjudication was incorrect. Among the 39 patients with a baseline deficit, 25 (64\%) had a deficit that showed at least some improvement. Only 1 patient (2.6\%) had a VF deficit that exhibited worsening from baseline at
6 months, which was accompanied by a deterioration in VA. The same patient had improvement of a baseline $\mathrm{CN}$ VI palsy.

Of the 43 distinct baseline deficits (observed in 25 patients) that had improved by the 6-month follow-up, $26(61 \%)$ had moderately improved, 8 (19\%) had highly improved, and 9 (21\%) had completely resolved. We observed single new deficits in 5 patients $(5 \%)$ at 6 months postprocedure: 3 moderate $\mathrm{CN}$ VI palsies, 1 moderate $\mathrm{CN}$ IV palsy, and 1 moderate VA deficit. Three of these new deficits (2 CN VI palsies and the CN IV palsy) developed in patients who did not have deficits at the baseline presentation (represented in Fig. 2 by a colored rectangle with horizontal hatching). A new CN VI palsy appeared in a patient who had a preexisting CN III palsy that had moderately improved by the 6-month follow-up. The VA deficit appeared in the patient with the worsening baseline VF 

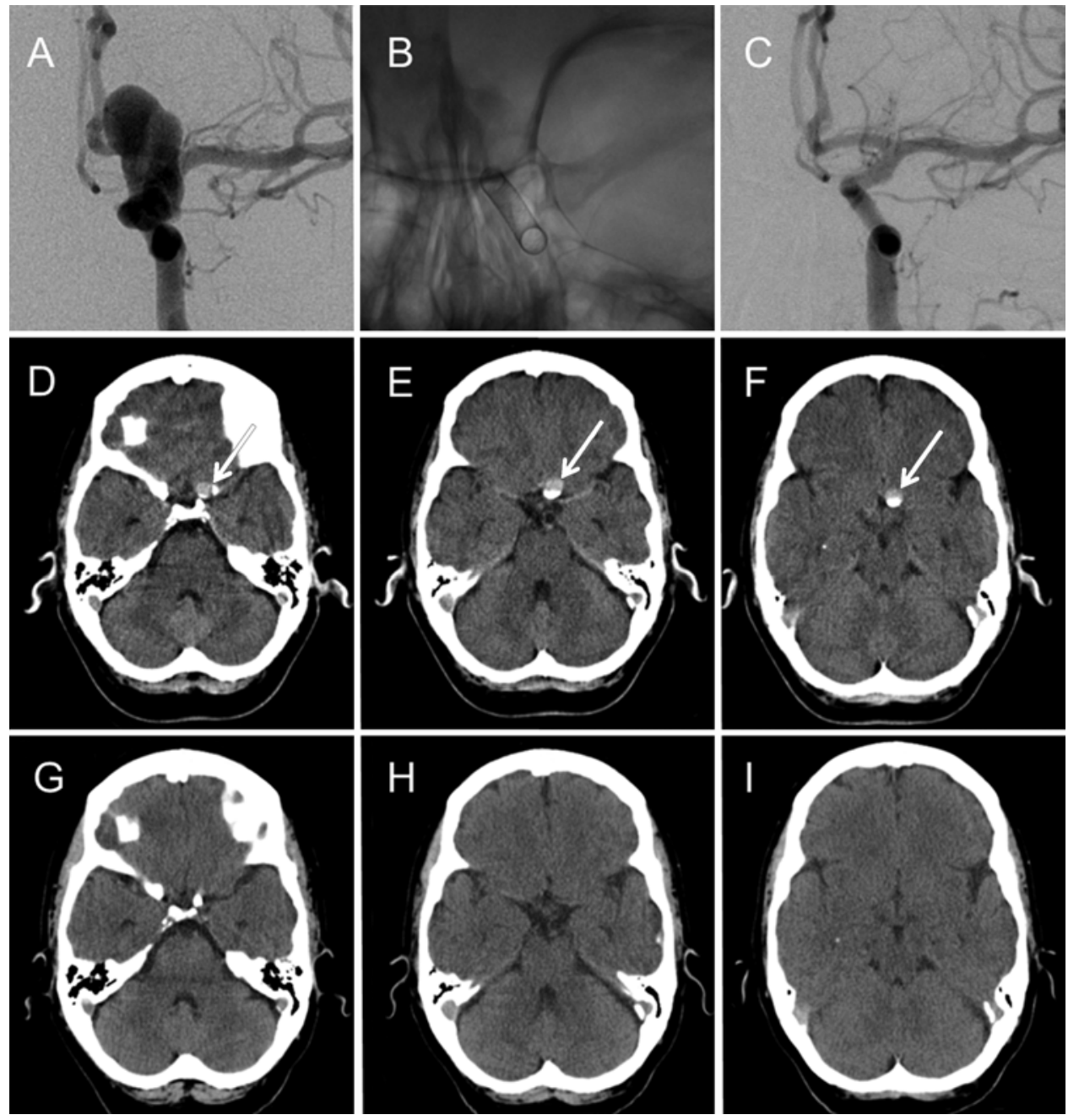

FIG. 1. Preembolization and postembolization imaging results of PED treatment for a large paraophthalmic segment aneurysm of the left ICA. A: Arterial-phase digital subtraction angiogram (frontal projection) showing a large, complex-neck cerebral aneurysm arising from the ophthalmic segment of the left ICA. B: Unsubtracted frontal radiographic image showing the PED deployed within the left ICA. C: Arterial-phase digital subtraction angiogram (the same projection as in B) taken at the 6-month follow-up, confirming occlusion of the aneurysm. D-F: Serial transaxial CT scans of the head immediately after treatment, showing contrast-blood level within the fundus of the ophthalmic segment aneurysm (arrows). G-I: Serial transaxial CT scans 6 months after treatment, showing involution of the aneurysm.

deficit, but moderately improved CN VI palsy. Six patients (6\%) with baseline deficits that were considered not likely to be related to the aneurysm $(1$ with a deficit of unclear relationship to the aneurysm and 5 with deficits that were presumed unlikely to be related to the aneurysm) showed improvement in their deficits. Two of these patients had moderate improvement in VFs, both ipsilateral and contralateral to the aneurysm; 1 had moderate improvement in ipsilateral VF; 2 showed completely resolved VF deficit -1 with resolution in both ipsilateral and contralateral fields; and 1 exhibited complete resolution of a CN VI palsy.

Overall, 17 patients showed symptoms of a compressive optic neuropathy (that is, findings of VF or VA deficits or APD), which were presumed to be related to the aneurysm at baseline, with 9 of these patients (53\%) showing any improvement in these symptoms. In total, 27 patients presented with any combination of CN III, IV, and VI palsies, 17 of whom (63\%) showed any improvement in symptoms. Three patients showed symptoms of trigeminal neuralgia, 1 of whom (33\%) showed any improvement in these symptoms.

Univariate analysis of factors associated with neuroophthalmological improvement after PED treatment indicated only 1 characteristic that reached statistical significance. None of the 4 patients with diabetes who presented with a baseline deficit showed an improvement in their deficits ( $p$ $=0.012$ by 2 -sided Fisher's exact test). The maximum dimension of an aneurysm was significantly larger in patients in whom examinations revealed a new or worse finding at 6 months postprocedure than in those in whom findings were stable or improved: $25.5 \pm 4.1 \mathrm{~mm}$ for the patients with worse outcomes versus $17.9 \pm 6.5 \mathrm{~mm}$ in those with stable or improved outcomes ( $\mathrm{p}=0.013,2$-tailed independent samples t-test). Four of the 5 patients whose examination indicated worsening of their neuroophthalmological 
TABLE 3. Neuroophthalmological findings attributable to the aneurysm stratified by aneurysm neck location*

\begin{tabular}{|c|c|c|c|c|c|c|c|c|c|}
\hline \multirow[b]{2}{*}{ Deficit/CN Affected } & \multicolumn{9}{|c|}{ Aneurysm Neck Location } \\
\hline & Petrous & Cavernous & Carotid Cave & Sup Hypophysial & Lat Clinoidal & Paraophthalmic & Supraclinoid & PCoA & $\mathrm{p}$ Value \\
\hline VF & - & $6(14.3)$ & - & $2(22.2)$ & $1(50.0)$ & $6(20.0)$ & $1(12.5)$ & $1(100.0)$ & 0.310 \\
\hline CN III & - & $13(31.0)$ & $1(50.0)$ & - & - & - & - & $1(100.0)$ & 0.001 \\
\hline CN IV & - & - & - & - & - & - & $1(12.5)$ & - & 0.120 \\
\hline CN V & - & $3(7.1)$ & - & - & - & - & - & - & 0.760 \\
\hline CN VI & - & $17(40.5)$ & $1(50.0)$ & - & - & $2(6.7)$ & - & - & 0.004 \\
\hline APD & - & $5(11.9)$ & - & $2(22.2)$ & $1(50.0)$ & $6(20.0)$ & $1(12.5)$ & $1(100.0)$ & 0.240 \\
\hline VA & - & $1(2.4)$ & - & $2(22.2)$ & $1(50.0)$ & $4(13.3)$ & $1(12.5)$ & - & 0.210 \\
\hline $\begin{array}{l}\text { No symptoms attribut- } \\
\text { able to the aneurysm }\end{array}$ & $4(100.0)$ & $18(42.9)$ & $1(50.0)$ & $7(77.8)$ & $1(50.0)$ & $22(73)$ & $6(75.0)$ & $0(0.0)$ & 0.058 \\
\hline $\begin{array}{l}\text { No. of pts w/ aneurysm } \\
\text { neck at location }\end{array}$ & 4 & 42 & 2 & 9 & 2 & 30 & 8 & 1 & NA \\
\hline
\end{tabular}

findings had cavernous segment aneurysms. In these patients, the smallest aneurysm was $19.4 \mathrm{~mm}$ in maximum dimension and the largest was $30.0 \mathrm{~mm}$.

In aggregate, $80(82 \%)$ of the aneurysms treated in the PUFS trial and evaluated at the 6-month follow-up showed angiographic occlusion, 8 (8\%) had a neck remnant, 8 (8\%) resulted in a residual aneurysm, and $2(2 \%)$ had indeterminate changes with respect to procedure-related efficacy. Of the 25 patients with symptomatic aneurysms at the time of treatment and who clinically improved, 21 (84\%) had complete occlusion of their aneurysm at 6 months post-PED implantation. In contrast, only 9 aneurysms (64\%) in the 14 patients whose baseline deficits did not improve were occluded at 6 months, but this difference failed to reach statistical significance $(p=0.16$, chi-square test).

\section{Discussion}

To the best of our knowledge, this study is the first to report the neuroophthalmological findings from endovascular stent-only reconstruction of large and giant ICA aneurysms. For the purpose of this study, the data in the analyses reported here were collected from thorough neuroophthalmological examinations both before and 6 months after PED treatment. Even given the relatively brief followup period of 6 months, the results are striking, with $64 \%$ of patients experiencing an objective improvement from their baseline deficit after treatment of their aneurysms with PED.

Drawing meaningful comparisons between the results presented here and those reported in the literature is limited by differences in design, end point definition, and patient cohorts between our study and those of other authors. Many of these previous studies have no defined threshold for reporting that a symptom has changed from baseline, ${ }^{1,13,15,16}$ while only 2 define a clear threshold. .,11 $^{4}$ Likewise, most of the studies examining changes in extraocular motor function nonspecifically include changes in both the objective extraocular motor examination and a patient's perception of double vision as a broad single outcome measure,,$^{1,4,13,15,16}$ as opposed to relying purely on the objective extraocular motor examination.

The inclusion of a patient's subjective experience of double vision in the broad metric of extraocular motor function does not account for circumstances in which the perception of double vision may change in the absence of improved extraocular motor function. Two of the aforementioned studies provide evidence that patients with no improvement in oculomotor paresis, or who even have worsening paresis, may have decreased perception of double vision. Stiebel-Kalish et al. ${ }^{13}$ note that 2 of their patients had worsening of misalignment, but their diplopia was unnoticed on a follow-up examination, using a primary end point of "resolved, improved, or became unnoticed" for following up patients who initially presented with oculomotor palsies. What the authors did not address explicitly was the number of patients whose misalignment remained unchanged on physical examination, but who reported that their diplopia had improved or became unnoticed. Another study reported that 19 patients had baseline diplopia and 23 had ophthalmoparesis, clearly suggesting that a reasonable proportion of patients with ophthalmoparesis do not report double vision. ${ }^{4}$ The change in the perception of double vision is an interesting subject and is likely dependent on patient age and duration of symptoms, but does little to address the question of restoration of $\mathrm{CN}$ function following $\mathrm{CN}$ decompression. ${ }^{2}$

The aneurysm treatment series most similar to that reported here come from a retrospective study of 17 patients with large ophthalmic segment aneurysms and symptoms of anterior optic pathway compression treated with endovascular therapy (16 patients were initially treated with endosaccular coils and 1 with arterial occlusion). ${ }^{5}$ The aneurysms of patients included in this series each had a neck size of at least $4 \mathrm{~mm}$ and a dome size of at least $10 \mathrm{~mm}$, which are anatomical thresholds shared by aneurysms in our study. That retrospective study reported that after the primary procedure, vision improved in $38 \%$ of the patients, remained unchanged in $25 \%$, and worsened in $38 \%$. In addition, 12 patients in the original cohort underwent 13 addi- 


\begin{tabular}{|c|c|c|c|c|c|c|c|c|c|}
\hline \multirow[b]{2}{*}{$\begin{array}{l}\text { Aneurysm } \\
\text { Location }\end{array}$} & \multirow{2}{*}{$\begin{array}{c}\text { Max } \\
\text { Dimension } \\
(\mathrm{mm})\end{array}$} & \multicolumn{8}{|c|}{ Cranial Nerve/Ophthalmologic Deficit } \\
\hline & & $\begin{array}{l}\text { VF } \\
\text { Ipsilat }\end{array}$ & $\begin{array}{c}\text { VF } \\
\text { Contralat }\end{array}$ & APD & VA & $\mathrm{CN}$ III & CN IV & $\mathrm{CN} \mathrm{VI}$ & $\mathrm{CN} \mathrm{V}$ \\
\hline Cavernous & 12.2 & & & & & & & & \\
\hline Cavernous & 25.2 & & & & & & & & \\
\hline Cavernous & 14.4 & & & & & & & & \\
\hline Cavernous & 23.5 & & & & & & & & \\
\hline Supraclinoid & 10.6 & & & & & & & & \\
\hline Cavernous & 19.4 & & & & & & $\bar{~}$ & & \\
\hline Cavernous & 25.7 & & & & & & & & \\
\hline Petrous & 28.1 & & & & & & & & \\
\hline Cavernous & 28.1 & & & & & & & & \\
\hline Cavernous & 26.8 & & & & & & & & \\
\hline Cavernous & 26.2 & & & & & & & & \\
\hline Cavernous & 26.1 & & & & & & & & \\
\hline Cavernous & 22.8 & & & & & & & & \\
\hline Paraophthalmic & 11.5 & & & & & & & & \\
\hline Cavernous & 22.2 & & & & & & & & \\
\hline Paraophthalmic & 16.1 & & & & & & & & \\
\hline Cavernous & 26.2 & & & & & & & & \\
\hline Cavernous & 25.0 & & & & & & & & \\
\hline Sup hypophysial & 10.1 & & & & & & & & \\
\hline Petrous & 14.4 & & & & & & & & \\
\hline Paraophthalmic & 12.5 & & & & & & & & \\
\hline Cavernous & 15.1 & & & & & & & & \\
\hline Paraophthalmic & 20.4 & & & & & & & & \\
\hline Cavernous & 30.0 & & & & & & & & \\
\hline Cavemous & 21.6 & & & & & & & & \\
\hline Cavernous & 17.2 & & & & & & & & \\
\hline Cavernous & 30.1 & & & & & & & & \\
\hline Cavernous & 22.1 & & & & & & & & \\
\hline Cavernous & 27.0 & & & & & & & & \\
\hline Carotid cave & 28.0 & & & & & & & & \\
\hline Cavernous & 27.3 & & & & & & & & \\
\hline Cavernous & 22.1 & & & & & & & & \\
\hline $\mathrm{PCOA}$ & 10.9 & & & & & & & & \\
\hline Cavernous & 24.1 & & & & & & & & \\
\hline Paraophthalmic & 23.0 & & & & & & & & \\
\hline Sup hypophysial & 18.0 & & & & & & & & \\
\hline Lat clinoidal & 18.0 & & & & & & & & \\
\hline Cavernous & 25.6 & & & & & & & & \\
\hline Paraophthalmic & 26.1 & & & & & & & & \\
\hline Paraophthalmic & 21.0 & & & & & & & & \\
\hline Paraophthalmic & 25.0 & & & & & & & & \\
\hline Sup hypophysial & 28.0 & & & & & & & & \\
\hline Supraclinoid & 22.5 & & & & & & & & \\
\hline Cavernous & 32.5 & & & & & & & & \\
\hline Cavernous & 15.4 & & & & & & & & \\
\hline
\end{tabular}

\begin{tabular}{|c|c|}
\hline Completely resolved & \\
\hline Highly improved & \\
\hline Moderately improved & \\
\hline Stable & \\
\hline Moderately worse & \\
\hline Markedly worse & \\
\hline Cannot tell & \\
\hline No baseline deficit & 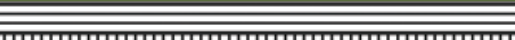 \\
\hline
\end{tabular}

FIG. 2. Color-coded depiction of neuroophthalmological outcomes in patients who showed symptoms of an aneurysm and who were treated with a PED. Each row represents an individual aneurysm with corresponding baseline deficits presumed to be attributable to the aneurysm. Colors (see color key below the table) represent the 6-month outcomes: blue indicates improvement/ resolution, red depicts worsening, and gray represents no change. Those deficits that were not initially thought to be attributable to the aneurysm but that had improved 6 months after the treatment are represented by rectangles with vertical hatching. New deficits at the 6-month follow-up are represented by rectangles with horizontal hatching.

tional procedures over a mean follow-up period of 2.9 years (including ICA occlusion in 7 earlier coiled aneurysms, repeated coil therapy in 5 , and optic nerve decompression in 1 case) to address unresolved clinical issues related to an- eurysm recurrence. Given that $5(56 \%)$ of the 9 patients in our series presenting with VA deficits showed improvement at the 6-month follow-up (that is, these deficits had highly improved in 3 patients and had moderately improved in 2 
patients) and that these deficits had remained stable or had not worsened in the other 4 patients, the potential of the stent-only construct for alleviating mass effect and the resultant compressive neuropathy becomes clear.

The relatively brief follow-up period in this analysis may limit our estimation of the ultimate therapeutic benefit of PED. In a retrospective study of patients with $\mathrm{CN}$ palsies related to intracranial aneurysms of any location, ${ }^{11}$ the mean length of time between treatment and recovery was 69 days; however, some patients' recoveries took up to 300 days. Moreover, although we did not collect data on symptom duration, there is ample evidence that earlier intervention following symptom onset results in the highest likelihood of recovery from cranial or optic neuropathy. ${ }^{11}$ This observation may be important because the composition of the aneurysm cohort targeted by PUFS (large, complex neck lesions for which acceptable alternative therapies were lacking) may have contained a bias toward patients with longstanding symptoms.

Although the percentage of patients in PUFS who had improved neuroophthalmological symptoms and an occluded aneurysm at 6 months postprocedure was greater than that for individuals showing no improvement despite an occluded aneurysm (84\% vs $64 \%$ of patients, respectively), this difference did not reach statistical significance. The apparent lack of an association between aneurysm occlusion and symptom resolution may be attributable to heterogeneities in the study cohort, both with respect to the type of clinical symptom (VF deficits vs oculomotor palsies, not all of which might be expected to exhibit similar potentials for recoverability), and the duration of symptoms (some treated soon after symptom onset, potentially more likely to improve, and others with symptoms of long duration). Moreover, the small numbers of patients composing the cohort with unoccluded aneurysms at 6 months (18\%) left the study underpowered for detection of potential outcome trends due to procedural efficacy.

Another limitation of this study, from a neuroophthalmological standpoint, is that there was no control arm of untreated patients to enable a comparison with the natural history of neuroophthalmological changes in a matched cohort with large and giant ICA aneurysms. However, data from the literature suggest that patients are highly unlikely to do as well as reported here in the absence of any aneurysm treatment. In one retrospective series of cavernous segment aneurysms, ${ }^{4}$ none of 10 patients in a nontreatment arm showed improvement in their condition: symptoms were stable in 3 patients, and 7 patients had worsening neuroophthalmological outcomes during follow-up for at least 5 years and for a mean length of 11.8 years. In another retrospective series following up untreated patients with cavernous segment aneurysms, 10 of whom showed symptoms and 10 no symptoms, 3 of the patients with no symptoms developed symptoms over a median of 2.4 years and 4 of the 10 patients presenting initially with symptoms had worsening of their symptoms, while symptoms improved in only 2 of these patients. Our finding that $64 \%$ of the patients with baseline deficits had improvement of these deficits at the 6-month follow-up is well outside the expected natural history of neuroophthalmological symptoms due to mass effect from aneurysms in the anterior circulation.

\section{Conclusions}

We present the neuroophthalmological outcomes from the prospective PUFS trial with PEDs, which is the first fully endoluminal, coil-free, vessel-sparing endovascular system for treating large and giant aneurysms. In our cohort, $40 \%$ of the patients presented with neuroophthalmological deficits at baseline presentation, and maximum aneurysm size was significantly correlated with these baseline symptoms. Overall, $64 \%$ of the patients with a baseline deficit showed at least some improvement after treatment with PED, while 5\% of the treated patients had a new deficit at 6 months. In addition, $6 \%$ of the patients showed improvement in a deficit that was presumed either unlikely to be related to the aneurysm or to have an unknown relationship with the aneurysm. Overall, individuals with diabetes were less likely to show improvement in baseline deficits over the 6 months posttreatment, and having a larger aneurysm was associated with new or worsening deficits. When compared with outcomes of previously reported series, these results are encouraging. There is ample evidence from the literature that a 6-month followup period may be too short to capture the total number of patients who will ultimately benefit from treatment, which leaves open the possibility for continued clinical improvement among our patients who showed aneurysm symptoms at baseline.

\section{References}

1. Bavinzski G, Killer M, Ferraz-Leite H, Gruber A, Gross CE, Richling B: Endovascular therapy of idiopathic cavernous aneurysms over 11 years. AJNR Am J Neuroradiol 19:559_ 565,1998

2. Becske T, Kallmes DF, Saatci I, McDougall CG, Szikora I, Lanzino G, et al: Pipeline for uncoilable or failed aneurysms: results from a multicenter clinical trial. Radiology 267:858868,2013

3. Choulakian A, Drazin D, Alexander MJ: Endosaccular treatment of 113 cavernous carotid artery aneurysms. J Neurointerv Surg 2:359-362, 2010

4. Goldenberg-Cohen N, Curry C, Miller NR, Tamargo RJ, Murphy KP: Long term visual and neurological prognosis in patients with treated and untreated cavernous sinus aneurysms. J Neurol Neurosurg Psychiatry 75:863-867, 2004

5. Heran NS, Song JK, Kupersmith MJ, Niimi Y, Namba K, Langer DJ, et al: Large ophthalmic segment aneurysms with anterior optic pathway compression: assessment of anatomical and visual outcomes after endosaccular coil therapy. J Neurosurg 106:968-975, 2007

6. Kupersmith MJ, Hurst R, Berenstein A, Choi IS, Jafar J, Ransohoff J: The benign course of cavernous carotid artery aneurysms. J Neurosurg 77:690-693, 1992

7. Kupersmith MJ, Stiebel-Kalish H, Huna-Baron R, Setton A, Niimi Y, Langer D, et al: Cavernous carotid aneurysms rarely cause subarachnoid hemorrhage or major neurologic morbidity. J Stroke Cerebrovasc Dis 11:9-14, 2002

8. Linskey ME, Sekhar LN, Hirsch WL Jr, Yonas H, Horton JA: Aneurysms of the intracavernous carotid artery: natural history and indications for treatment. Neurosurgery 26:933938, 1990

9. Nanda A, Javalkar V: Microneurosurgical management of ophthalmic segment of the internal carotid artery aneurysms: single-surgeon operative experience from Louisiana State University, Shreveport. Neurosurgery 68:355-371, 2011

10. Nelson PK, Lylyk P, Szikora I, Wetzel SG, Wanke I, Fiorella 
D: The pipeline embolization device for the intracranial treatment of aneurysms trial. AJNR Am J Neuroradiol 32:34-40, 2011

11. Panagiotopoulos V, Ladd SC, Gizewski E, Asgari S, Sandalcioglu EI, Forsting M, et al: Recovery of ophthalmoplegia after endovascular treatment of intracranial aneurysms. AJNR Am J Neuroradiol 32:276-282, 2011

12. Pickett GE, Laitt RD, Herwadkar A, Hughes DG: Visual pathway compromise after hydrocoil treatment of large ophthalmic aneurysms. Neurosurgery 61:E873-874, 2007

13. Stiebel-Kalish H, Kalish Y, Bar-On RH, Setton A, Niimi Y, Berenstein A, et al: Presentation, natural history, and management of carotid cavernous aneurysms. Neurosurgery 57:850-857, 2005

14. Turner RD, Byrne JV, Kelly ME, Mitsos AP, Gonugunta V, Lalloo S, et al: Delayed visual deficits and monocular blindness after endovascular treatment of large and giant paraophthalmic aneurysms. Neurosurgery 63:469-475, 2008

15. van der Schaaf IC, Brilstra EH, Buskens E, Rinkel GJ: Endovascular treatment of aneurysms in the cavernous sinus: a systematic review on balloon occlusion of the parent vessel and embolization with coils. Stroke 33:313-318, 2002

16. van Rooij WJ, Sluzewski M: Unruptured large and giant carotid artery aneurysms presenting with cranial nerve palsy: comparison of clinical recovery after selective aneurysm coiling and therapeutic carotid artery occlusion. AJNR Am J Neuroradiol 29:997-1002, 2008
17. Xu DS, Hurley MC, Batjer HH, Bendok BR: Delayed cranial nerve palsy after coiling of carotid cavernous sinus aneurysms: case report. Neurosurgery 66:E1215-E1216, 2010

\section{Author Contributions}

Conception and design: Nelson, Fouladvand, Becske, Berez, Cher, Fiorella. Acquisition of data: all authors. Analysis and interpretation of data: Nelson, Sahlein, Fouladvand, Berez, Cher. Drafting the article: Nelson, Sahlein, Cher. Critically revising the article: Nelson, Sahlein, Becske, Cher. Reviewed submitted version of manuscript: Nelson, Sahlein, Becske, Cher. Approved the final version of the manuscript on behalf of all authors: all authors. Statistical analysis: Nelson, Sahlein, Cher. Administrative/technical/material support: Nelson, Berez, Cher. Study supervision: Nelson, Sahlein, Fouladvand, Becske, Saatci, McDougall, Szikora, Lanzino, Moran, Lopes, Berez, Cher, Siddiqui, Levy, Albuquerque, Fiorella, Berentei, Marosfoi, Cekirge, Kallmes.

\section{Correspondence}

Peter Kim Nelson, NYU Langone Medical Center, 660 First Ave., 7th Fl., New York, NY 10016. email: nelsop01@med.nyu. edu. 